\title{
A CONCLUSÃO DO ENSINO MÉDIO E A DIFÍCIL TAREFA DE REALIZAR A ESCOLHA PROFISSIONAL
}

\author{
Maria Luzia Silva Mariano, Amanda Lays Monteiro Inácio \\ Universidade Estadual de Londrina - UEL, Programa de Mestrado e Doutorado em Educação, Londrina/Paraná, E-mail: \\ malumariano@yahoo.com.br.
}

\begin{abstract}
RESUMO
Ao se considerar as especificidades inerentes à adolescência, bem como a necessidade da escolha profissional ser condizente com esse período do desenvolvimento, se fazem necessários apontamentos acerca da maturidade desses jovens para a tomada de decisão, bem como a importância do incentivo governamental para essa faixa etária. O objetivo deste estudo foi investigar a maturidade para a escolha profissional em 524 alunos do Ensino Médio em dois estados brasileiros por meio da Escala de Maturidade para a Escolha Profissional (EMEP). Os resultados indicaram que os alunos apresentam classificação média para a maturidade da escolha profissional, não sendo possível encontrar evolução progressiva na maturidade total apresentada pelos mesmos. Diante dos resultados, evidencia-se a necessidade de investigações futuras acerca do tema visando sua melhor compreensão e são expostas algumas possibilidades sobre essa temática.
\end{abstract}

PALAVRAS-CHAVE: Maturidade; Escolha Profissional; Ensino Médio; Educação; Adolescência.

\section{THE CONCLUSION OF MIDDLE SCHOOL AND THE DIFFICULT TASK OF MAKING A PROFESSIONAL CHOICE}

\begin{abstract}
When considering the specific characteristics inherent to adolescence, as well as the need for professional choice to be consistent with this period of development, it is necessary to note the maturity of these youngsters for decision making, as well as the importance of the governmental incentive for this age group. The objective of this study was to investigate the maturity for the professional choice in 524 high school students in two Brazilian states through the Professional Choice Maturity Scale (EMEP). The results indicated that the students present average scores for the maturity of the professional choice, and it is not possible to find progressive evolution in the total maturity presented by the same. In view of the results, it is evident the need for future research on the subject aiming at its better understanding and some possibilities are exposed on this theme.
\end{abstract}

KEYWORDS: maturity, professional choice, high school, education, adolescence. 


\section{INTRODUÇÃO}

Mesmo com as políticas de incentivo que existem atualmente para a continuidade dos estudos após a finalização da educação básica, evidencia-se a falta de iniciativas governamentais que orientem de maneira objetiva e façam com que os jovens reflitam acerca da escolha profissional, que normalmente é realizada ao final do Ensino Médio. Outra questão preocupante, é que não se leva em conta os motivos que fazem com que esses jovens alunos cursem o ensino médio ou mesmo pensem em uma carreira futura (MARIANO, 2015).

A etapa do Ensino Médio condiz com a faixa etária da adolescencia, que pode ser considerada como uma fase permeada por diversas especificidades que a diferenciam da infância e da vida adulta, sendo caracterizada como um momento de transição (COLOMBO; PRATTI, 2014). Nesse sentido, Lucchiari (1993), afirma que a escolha da profissão é uma necessidade e coincide com uma fase do desenvolvimento na qual os jovens estão passando por mudanças muito significativas em suas vidas e é nesse contexto que surgem as dificuldades na tomada de decisão, que muitas vezes sofrem influências do contexto social e familiar.

A tarefa de fazer uma escolha profissional se tornou ainda mais difícil com o advento da globalização, pois o adolescente precisa escolher entre as diversas opções que lhes são oferecidas. Se optar por um curso de graduação, ele precisa considerar o tempo do curso, o custo para se manter na universidade, o potencial de empregabilidade ou ainda o grau de independência que ele conseguirá atingir ao se formar. No caso de optar pelo ingresso no mercado de trabalho, a reflexão deve ser acerca da remuneração, da possibilidade de ascensão no trabalho escolhido e também nas constantes maneiras para se atualizar (CAMPOS, 2013).

A escolha da carreira é uma tarefa complexa e implica certa maturidade para que a tomada de decisão seja consciente e autônoma. A maturidade, conceitualmente, "se refere ao conjunto de atitudes e conhecimentos que o indivíduo acumula para realizar, de forma consciente e independente, sua escolha profissional" (COLOMBO; PRATTI, 2014, p.2). Para Neiva et al. (2005), ainda são poucos os jovens que conseguem tomar a decisão acerca de sua profissão de forma consciente e madura, de modo que muitos acabam abandonando seus projetos profissionais. Além disso, destaca-se o caráter multifatorial responsável por essa escolha, pois a maturidade que o aluno apresenta para realizar a escolha profissional está ligada a uma ampla rede de fatores que influenciam diretamente todo esse processo.

Esses fatores podem ser sociais, individuais, políticos, econômicos, culturais, familiares ou mesmo educacionais, influenciando direta ou indiretamente nas escolhas particulares de cada um. A adolescência é um período de muitas mudanças fisiológicas e psíquicas no qual as escolhas feitas acarretam mudanças também no papel social em que o indivíduo vai ocupar na sociedade em que está inserido. Por isso a escolha profissional pode ser considerada a grande escolha que deve ser feita nessa fase do desenvolvimento (ALMEIDA; MELO-SILVA, 2011; PAULA; DUTRA; VILAS BOAS, 2014). A literatura evidencia diversos estudos que buscam identificar a maturidade dos adolescentes no que se refere à escolha profissional. Na sequência são destacados dois desses estudos em ordem cronológica.

A maturidade para escolha profissional por meio de fatores como sexo, tipo de escola, turno de estudos e a série escolar do ensino médio foi verificada por Neiva et al. (2005). Para tanto, a EMEP foi aplicada em 950 alunos do ensino médio público e particular de uma cidade do estado do Paraná. Os resultados indicaram a existência de diferenças significativas na maturidade para a escolha profissional em função do sexo, do tipo de escola e da série escolar. O sexo feminino se mostrou mais maduro que o sexo masculino e os alunos de escola particular mostraram-se mais maduros que os de escola pública. Além disso, os alunos da terceira série se mostraram mais maduros do que os de primeira série. Entretanto, não foram observadas diferenças significativas na maturidade para a escolha profissional, em função do turno de estudo dos alunos. 
Junqueira e Melo-Silva (2014) utilizaram a EMEP para investigar a maturidade de 748 adolescentes de um serviço escola de orientação profissional considerando o perfil sociodemográfico e a evolução após intervenção. Os resultados desse estudo identificaram que a maioria dos sujeitos foi classificada com nível de maturidade abaixo de médio no início do atendimento. Já na comparação da maturidade antes e depois da intervenção, com 492 dos adolescentes, identificou-se que a intervenção favoreceu significativamente o desenvolvimento da maturidade para a escolha profissional.

Muitos outros estudos referentes à maturidade e escolha profissional podem ser encontrados na literatura científica, evidenciando a importância do tema em questão. Face ao que foi exposto, o presente estudo teve por objetivo investigar o nível de maturidade para a escolha profissional em alunos do Ensino Médio nos estados de Minas Gerais e Paraná. A seguir serão descritos os procedimentos metodológicos utilizados.

\section{METODOLOGIA}

Participantes

Participaram 524 alunos de três escolas públicas estaduais, duas do estado de Minas Gerais, representando $71 \%(n=372)$ e uma do estado do Paraná, representando $29 \%(n=152)$. Deste total, $57,8 \%(n=303)$ representou o sexo feminino e $42,2 \%(n=221)$ o sexo masculino. A idade média dos estudantes foi de 16 anos e 5 meses $(D P=1,49)$, sendo 14 anos a idade mínima e 27 a idade máxima. Do 1ㅇano, participaram 242 alunos $(46,2 \%)$ e do 3ㅇa ano 282 (53,8\%).

Instrumento

Utilizou-se a Escala de Maturidade para a Escolha Profissional (EMEP) da autoria de Neiva (1999) que apresenta 45 questões com alternativas de respostas dispostas em escala Likert de 5 pontos em que o aluno assinala com que frequência desenvolve a atividade descrita nas questões (sempre, frequente, às vezes, raramente e nunca). Esse instrumento teve por objetivo medir o grau de maturidade de cada aluno para escolher a sua futura profissão. Desse modo, o aluno analisa a questão proposta e responde de acordo com a frequência com que pensa na escolha profissional.

A pontuação da EMEP apresenta duas dimensões principais, que medem as Atitudes que o aluno apresenta frente à escolha profissional e os Conhecimentos necessários à escolha profissional, que são considerados essenciais para que eles atinjam a maturidade para a escolha profissional. A dimensão Atitudes é dividida em: Determinação para a escolha profissional; Responsabilidade para a escolha profissional; Independência na escolha profissional. A segunda dimensão, Conhecimentos, é composta por: Autoconhecimento; Conhecimento da Realidade educativa e socioprofissional. Cabe ressaltar que a escala teve sua segunda versão lançada no ano de 2014 , no entanto, no período em que se iniciou a coleta destinada ao presente estudo, a edição disponível era a do ano de 1999. Destaca-se também que a EMEP é um instrumento privativo para uso do Psicólogo, dessa formar a aplicação do questionário foi acompanhada por um Psicólogo em todos os seus dias de aplicação.

\section{Procedimentos}

O presente estudo foi submetido e aprovado (parecer no. 843.332) pelo Comitê de Ética em Pesquisa Envolvendo Seres Humanos (CEP) da Universidade Estadual de Londrina (UEL) à qual estava vinculado. Todos os procedimentos éticos para a realização deste estudo estão fundamentados nos dispositivos da Resolução 466/2012 e complementares do Conselho Nacional de Saúde.

A aplicação do instrumento ocorreu em sala de aula, de forma coletiva, em dia e horário agendados com as instituições participantes e teve duração aproximada de 50 minutos com cada 
turma. Somente participaram do estudo os alunos cujos pais ou responsáveis legais assinaram o termo de consentimento livre e esclarecido, bem como os alunos que consentiram na participação. Ressalta-se que os alunos do 20 ano não participaram, pois a intenção foi fazer uma análise transversal, e investigar se existem alterações na maturidade dos alunos de acordo com a evolução dos anos escolares.

Análise de dados

Os dados foram organizados em planilha do exel e submetidos à análise estatística descritiva e inferencial, com o intuito de atender ao objetivo proposto.

\section{RESULTADOS}

Ao responder as perguntas constantes na Escala de Maturidade para a Escolha Profissional, os alunos obtiveram pontuação em 5 diferentes subescalas, sendo elas: determinação, responsabilidade, independência, autoconhecimento e conhecimento da realidade profissional. A somatória dos pontos de cada subescala aferiu a maturidade total apresentada pelo aluno para realização da escolha profissional. O aluno poderia ser classificado em 7 diferentes níveis de maturidade, sendo 1 muito inferior, 2 inferior, 3 médio inferior, 4 médio, 5 médio superior, 6 superior e 7 muito superior.

Dessa forma, a análise descritiva da EMEP levantou as pontuações nas seguintes subescalas: determinação, responsabilidade, independência, autoconhecimento, conhecimento da realidade e maturidade total. A Tabela 1 mostra a média de pontos para cada subescala, a pontuação máxima e mínima para cada uma, o desvio padrão e a variação da pontuação para cada subescala.

Tabela 1. Média de pontos, desvio padrão, pontuação máxima e mínima e variação da pontuação para cada subescala da Escala de Maturidade para a Escolha Profissional.

\begin{tabular}{lccccc}
\hline \multicolumn{1}{c}{ Subescalas } & $\begin{array}{c}M \text { de } \\
\text { Pontos }\end{array}$ & $D P$ & $\begin{array}{c}\text { Pontuação } \\
\text { Mínima }\end{array}$ & $\begin{array}{c}\text { Pontuação } \\
\text { Máxima }\end{array}$ & $\begin{array}{c}\text { Variação da } \\
\text { Pontuação }\end{array}$ \\
\hline Determinação & 34,6 & 8,41 & 10 & 50 & $10-50$ \\
Responsabilidade & 36,5 & 15,0 & 3 & 33 & $10-50$ \\
Independência & 27,1 & 6,00 & 8 & 45 & $8-45$ \\
Autoconhecimento & 23,6 & 5,94 & 7 & 35 & $7-35$ \\
$\begin{array}{l}\text { Conhecimento da } \\
\text { Realidade Profissional }\end{array}$ & 31,1 & 5,93 & 10 & 50 & $10-50$ \\
Maturidade Total & 152,3 & 22,6 & 99 & 217 & $45-230$ \\
\hline
\end{tabular}

Fonte: Elaborado pelas autoras.

A análise descritiva da amostra indica que os alunos apresentam classificação média para a maturidade da escolha profissional. Esse dado fica evidente quando se observa que a pontuação para a maturidade total poderia chegar a 230 pontos. Dessa forma, a pontuação total dos alunos de uma maneira geral para a Escala de Maturidade para a Escolha Profissional foi classificada no nível médio, correspondendo a 39,5\% $(n=207)$ do total de alunos. 
Coincidentemente a média foi mantida em todas as outras subescalas do instrumento. A subescala determinação englobou $46,4 \%$ dos alunos $(n=243)$, a de responsabilidade $23,2 \%$ ( $n=153)$, a de independência enquadrou $49,2 \%$ dos estudantes ( $n=258)$, a subescala autoconhecimento $31,9 \%(n=167)$ e a subescala referente ao conhecimento da realidade abrangeu $43,7 \%(n=229)$ dos alunos.

No comparativo por estado das amostras, o estado do Paraná manteve a classificação média pra todas as subescalas. O estado de Minas Gerais apresentou variação da subescala referente à responsabilidade apresentada pelo aluno para a escolha profissional. O nível de maturidade aferido foi médio inferior em $29,3 \%(n=109)$ dos alunos. Em relação à comparação por ano escolar dos alunos, a amostragem geral não apresentou diferenças significativas. A comparação por ano feita considerando os alunos de cada estado separadamente também não apresentou diferenças significativas.

\section{DISCUSSÃO}

De acordo com Neiva (1999), a maturidade para a escolha profissional é composta por um conjunto de atitudes (determinação, responsabilidade, independência) e conhecimentos (autoconhecimento e conhecimento da realidade profissional) que o indivíduo deve apresentar para que possa realizar de forma madura e consciente sua escolha profissional. Considerando que os alunos do presente estudo encontram-se no nível de maturidade médio, é possível supor que estes apresentam certo nível dos conjuntos de atitudes e conhecimentos supracitados, no entanto ainda não estão de fato amadurecidos para fazer uma escolha sólida e consciente.

O sistema educacional brasileiro está organizado de maneira que em determinado momento do processo educacional o aluno faça uma escolha que possivelmente ele carregará por toda a sua vida adulta. Normalmente é ao final do Ensino Médio que essa escolha se dá, mas sem que esse aluno tenha sido preparado para escolher e sem que ele tenha a maturidade necessária. Isso acontece pelo fato do sistema educacional brasileiro não apresentar atividades que visem à orientação profissional ou vocacional de seus alunos (JUNQUEIRA, 2010).

Os estudantes paranaenses mantiveram a classificação média para todas as subescalas do instrumento bem como para a maturidade total. Já para o estado de Minas Gerais, a maioria dos alunos apresentou classificação média inferior para responsabilidade. De acordo com Neiva (1999), a responsabilidade do aluno para a escolha profissional se refere ao engajamento do indivíduo e a sua preocupação para realizar a escolha. É possível admitir que a baixa responsabilidade se dê ao fato de os alunos não apresentarem classificação mais alta para a maturidade total. Outra hipótese é a de que os professores desses alunos podem ter um perfil controlador, por exemplo, que exercem o controle externo por meio de recompensas ou punições, o que segundo Boruchovitch (2004), pode fazer com que o senso de responsabilidade dos alunos diminua. Destaca-se a necessidade de que tais dados sejam melhor investigados em estudos futuros.

Como já foi citado, na comparação entre os anos escolares dentro do seu estado, também não foram encontradas diferenças significativas na maturidade apresentada pelos alunos. Outros estudos foram realizados utilizando a EMEP a fim de aferir a maturidade dos alunos comparando o ano que o aluno está cursando, turno de estudo, sexo, instituição pública ou privada, dentre outros quesitos (Ver NEIVA, 1999; NEIVA et al., 2005). Nesses estudos foram encontradas evoluções progressivas nas subescalas e também na maturidade total apresentada pelos alunos conforme a série escolar em que se encontram. No entanto, no presente estudo, a progressão das evoluções citadas não foi encontrada, não sendo possível enunciar com precisão os motivos para a falta de progressão na maturidade dos alunos. A questão é interessante, e merece ser investigada com maior profundidade em pesquisas futuras, visando a sua melhor compreensão. 


\section{CONCLUSÃO}

O presente estudo buscou investigar o nível de maturidade para a escolha profissional em alunos do Ensino Médio, podendo-se afirmar diante dos resultados que os alunos apresentam classificação média para a maturidade da escolha profissional, não sendo possível encontrar evolução progressiva na maturidade total apresentada pelos mesmos. Diante do que foi exposto, reitera-se a importância da oferta de atividades que orientem a escolha profissional dos alunos proporciona o aumento da maturidade que eles apresentam para a realização da escolha profissional.

Os estudos citados comprovaram aumento significativo na maturidade apresentada pelos alunos após algum tipo de intervenção profissional ou vocacional ter sido realizada com os alunos. Dessa forma, destaca-se a relevância de parcerias que podem ser formadas entre as escolas e as universidades por meio de palestras ou minicursos, para que essa carência de conhecimento da realidade profissional dos alunos seja sanada. Além disso, cabe ressaltar o papel dos incentivos governamentais para essas e outras ações sejam realizadas com o intuito de possibilitar que o jovem reflita durante todo o ensino médio sobre sua escolha profissional.

\section{REFERÊNCIAS}

ALMEIDA, F. H.; MELO-SILVA, L. L. Influência dos pais no processo de escolha profissional dos filhos: uma revisão da literatura. Psico-USF (Impr.), v. 16, n. 1, p.75-85, 2011. Disponível em: http://www.scielo.br/scielo.php?script=sci_arttext\&pid=S1413-82712011000100009. Acesso em: 08 ago. 2017.

BORUCHOVITCH, E. A auto-regulação da aprendizagem e a escolarização inicial. In: BORUCHOVITCH, E.; BZUNECK, J. A. (Orgs). Aprendizagem: processos psicológicos e o contexto social na escola. Petrópolis, RJ: Vozes, 2004, p. 55 a 88.

CAMPOS, R. R. F. Indecisão profissional e otimismo em jovens aprendizes. 2013. Dissertação (Mestrado em Psicologia) - Programa de pós-graduação em Psicologia, Universidade São Francisco, Itatiba, 2013.

COLOMBO, G.; PRATTI, L. E. Maturidade para escolha profissional, habilidades sociais e inserção no mercado de trabalho. Revista Brasileira de Orientação Profissional, v. 15, n. 2, p.201-212, 2014. Disponível em: http://pepsic.bvsalud.org/pdf/rbop/v15n2/10.pdf. Acesso em 07 ago. 2017.

JUNQUEIRA, M. L. Maturidade para a escolha da carreira em adolescentes de um serviço de orientação profissional. 2010. Dissertação (Mestrado em Psicologia) - Programa de Pós-graduação em Psicologia, FFCLRP - Departamento de Psicologia e Educação, Universidade de São Paulo, Ribeirão Preto, 2010.

JUNQUEIRA, M L; MELO-SILVA, L. L. Maturidade para a escolha de carreira: estudo com adolescentes de um serviço-escola. Revista Brasileira de Orientação Profissional, São Paulo, v. 15, n. 2, p. 187-199, 2014. Disponível em:

http://pepsic.bvsalud.org/scielo.php?script=sci arttext\&pid=S1679-33902014000200009. Acesso em: 08 ago. 2017.

LUCCHIARI, D. H. P. S. Pensando e vivendo a orientação profissional. São Paulo: Summus, 1993. 
MARIANO, M. L. S. Qualidade Motivacional no Ensino Médio: Estudo sobre relações com a maturidade e a escolha profissional. 2015. Dissertação (Mestrado em Educação) - Universidade Estadual de Londrina, 2015.

NEIVA, K. M. C. Escala de Maturidade para a Escolha Profissional (EMEP): Manual. São Paulo, Vetor Editora Psicopedagógica. 1999.

NEIVA, K. M. C. et al. Um estudo sobre a maturidade para escolha profissional de alunos no ensino médio. Revista Brasileira de Orientação Profissional, São Paulo, v. 6, n. 1, p. 1-14, 2005. Disponível em: http://pepsic.bvsalud.org/pdf/rbop/v6n1/v6n1a02.pdf. Acesso em: 07 ago. 2017.

PAULA, A. V. D.; DUTRA, A. M.; VILAS BOAS, A. A. Percepções de adolescentes e seus cuidadores quanto ao nível de maturidade para escolha profissional - um estudo de caso. Revista FSA, Teresina, v. 11, n. 4, p. 206-218, 2014. Disponível em: http://www4.fsanet.com.br/revista/index.php/fsa/article/view/634. Acesso em 08 ago. 2017. 